\title{
Four cases of right-sided bundle-branch block and one case of atrioventricular block in three generations of a family
}

\author{
Erik E. Simonsen and Edi G. Madsen \\ From the Clinical Physiological Laboratory, The Municipal and County Hospital, Odense, \\ Denmark
}

Four cases of complete right bundle-branch block and one case of atrioventricular heart block, all occurring within three generations of the same family, are described. The 4 patients with bundlebranch block had no symptoms, whereas the patient with atrioventricular heart block suffered Adams-Stokes attacks from the age of 13 and died at 47 years of age. $A$ 33-year-old man with bundle-branch block had a normal electrocardiogram at the age of 7 , suggesting that inherited bundle-branch block does not necessarily manifest itself during the first years of life.

Familial incidence of disturbances of conduction in the heart has been described on rare occasions. The authors have found reports of 3 I cases of atrioventricular block in II families (Wendkos and Study, 1947; Connor et al., 1959; Wallgren and Agorio, 1960; Lynch and Engle, 196r; Stéphan, 196r; Combrink, Davis, and Snyman, 1962; Crittenden, Latta, and Ticinovich, 1964; Khorsandian, Moghadam, and Müller, 1964; Gazes et al., 1965; Tsagaris, Bustamante, and Friesendorff, I967; Veracochea et al., 1967). In two of these families (Combrink et al., 1962; Gazes et al., I965), four and three cases of right-sided bundle-branch block, respectively, were encountered in other members of the families. Right-sided bundle-branch block was described in three and five cases in two families (Mosetti, I954; Trivella and Chella, 1960), and left-sided bundle-branch block was described in two and four cases in two families (Martínez Aparicio, 195I; DeForest, 1956). The present paper presents four cases of right-sided bundle-branch block and one case of atrioventricular block in three generations of the same family.

\section{Case reports}

Case I The patient was a 48-year-old female cashier. She was healthy until the age of 13 years, when she had to give up Girl Guide activities on account of recurrent syncope. In I927, at 16 years she was admitted to the local hospital because of syncope, with a pulse rate of 24 a minute.

Received 25 November 1969.
Later in 1927 she was admitted to the University Hospital in Copenhagen. The diagnosis of atrioventricular block with Adams-Stokes attacks was established. Objective investigation revealed a normally developed girl with no dyspnoea, cyanosis, or signs of cardiac insufficiency. A systolic murmur was heard in the second intercostal space on the left side. The blood pressure was $90 / 60 \mathrm{~mm}$. Hg. On 22 November 1927 the electrocardiogram showed third degree atrioventricular block, and on 9 January 1928 sinus rhythm with PR interval of $0.14 \mathrm{sec}$. In both these electrocardiograms, the QRS complexes were normal.

Until 1944, the patient had Adams-Stokes seizures at intervals of I to 2 years. After 1944, these increased in frequency, and from I95I she had attacks at intervals of 2 to 4 weeks. In 1956 she was treated with ephedrine hydrochloride $20 \mathrm{mg}$. $\times 5$ without any effect on the pulse rate or the Adams-Stokes seizures.

Between attacks she had no cardiac symptoms. At the age of 20 and 21 she had two normal pregnancies. At the age of 40 , a therapeutic abortion was performed on account of Adams-Stokes attacks. The frequency of the seizures did not increase during pregnancies.

In 1944, 1951, and 1956 she was admitted to the Medical Department B in Odense on account of Adams-Stokes seizures. The stethoscopic findings were unchanged. The blood pressure varied between 140/90 and 110/70 mm. Hg. Neither cardiac decompensation nor other complicating conditions were found. The appearance of the electrocardiogram varied during all the periods in hospital.

In I944, the patient had third degree atrioventricular block and bundle-branch block on the left side. In 195I, sinus rhythm and right-sided 
bundle-branch block were present. On 7 January 1956 the patient had second degree atrioventricular block, with normal QRS complexes, while, the next day, third degree atrioventricular block and right-sided bundle-branch block were found, and three days later, sinus rhythm and right-sided bundle-branch block (Fig. I).

$X$-ray examination of the heart in 1956 revealed that the cardiothoracic ratio was 56 . The increase in size was localized to the left ventricle while the right ventricle and the pulmonary arch were normal.

She died in 1959 in her home at the age of 48 years presumably during an Adams-Stokes seizure. No necropsy was performed.

Case 2 This patient, a housewife aged 38 years, was the daughter of Case r. She had always been healthy, was capable of doing ordinary housework, and could ride a bicycle without discomfort. She had two normal pregnancies at the ages of 23 and 26 years.

Investigations in 1968 showed a normal woman. Stethoscopic examination of the heart was normal and the blood pressure was $\mathrm{Iro} / 80 \mathrm{~mm}$. $\mathrm{Hg}$. Electrocardiographic examination revealed rightsided bundle-branch block (Fig. 2). $X$-ray examination of the heart was normal.

Case 3 This patient, a hospital porter aged 37 years, was the son of Case I. He had never had rheumatic fever, diphtheria, or tuberculosis.

At the age of 7 years, he was admitted on account of malaise. Objective investigation, electrocardiographic and $x$-ray examination of the thorax were normal.

In 1965 , at the age of 33 years, he was submitted to operation for acute appendicitis. During this episode the electrocardiogram indicated rightsided bundle-branch block. He had never had symptoms of cardiac disease and was able to fulfil his duties as hospital porter.

Investigation in 1968 showed a slender man. Stethoscopic examination of the heart was normal, and the blood pressure was $120 / 80 \mathrm{~mm}$. Hg. Electrocardiogram recorded at rest and during exercise showed sinus rhythm and right-sided bundle-branch block (Fig. 2). $X$-ray examination of the heart was normal. Right- and left-sided cardiac catheterization and angiocardiography indicated nothing abnormal.

Case 4 She was the second of Case 3's children. In 1967, at the age of 7 years, she was admitted to the Pediatric Department on account of a systolic murmur. She had always been healthy.

The patient was a little thin, but otherwise normally developed girl. Stethoscopic examination of the heart revealed a systolic murmur of first degree in the second left intercostal space, and the second heart sound was constantly reduplicated. The blood pressure was $95 / 60 \mathrm{~mm}$. Hg. Electrocardiogram revealed sinus rhythm and right-sided bundle-branch block. Radiography of the heart showed normal findings. Right-sided cardiac catheterization and angiocardiography revealed normal conditions.

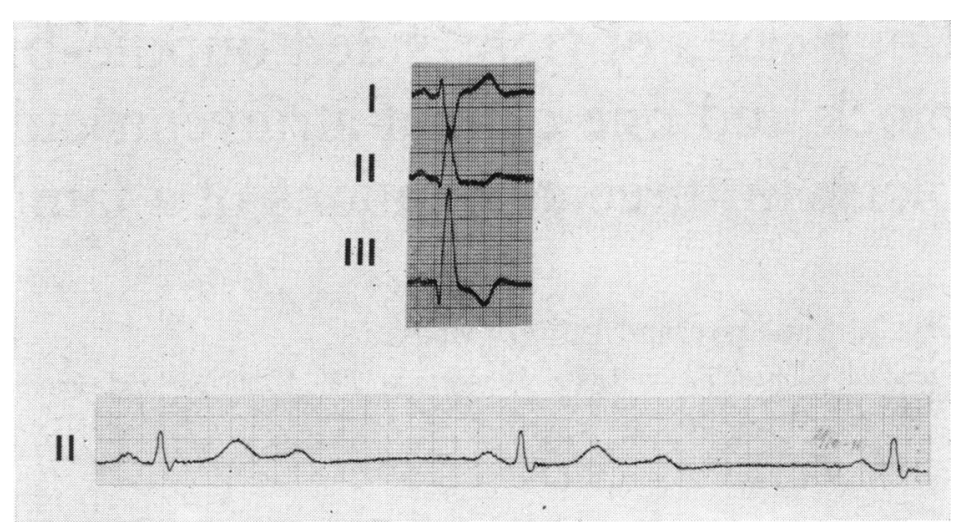

FIG. I Electrocardiogram from Case I. The upper one was recorded in 1951 and shows sinus rhythm and right-sided bundle-branch block. The lower one was recorded in 1956 and shows second degree atrioventricular block, with normal $Q R S$ complexes.

Case 5 This patient, the daughter of a sister of Case I, was a 21-year-old typist and had always been healthy. She was capable of doing ordinary housework and could ride a bicycle without discomfort.

Objective investigation in 1968 revealed a slender woman with neither dyspnoea nor cyanosis. Stethoscopic examination of the heart was normal and the blood pressure was $115 / 65 \mathrm{~mm}$. $\mathrm{Hg}$. Electrocardiogram showed sinus rhythm and right-sided bundle-branch block (Fig. 2). Radiographic examination of the heart was normal.

Family data The father of Case I died at the age of 68 years from myelomatosis, and the mother died at the age of 28 years, according to the family, from Spanish influenza. No electrocardiographic recordings had been made in either

FIG. 2 Electrocardiogram showing sinus rhythm and right-sided bundle-branch block from Cases 2, 3, 4, and 5.

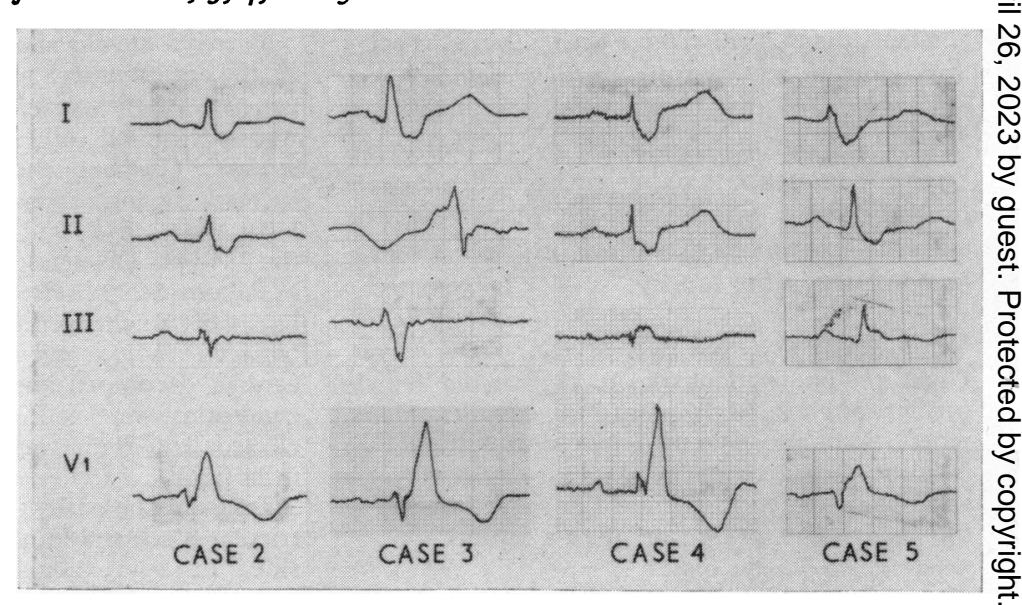


of them. The authors have investigated 22 further members of this family in view of electrocardiographic changes and evidence of heart disease. Normal conditions were encountered in all. One member refused to co-operate in the investigation, and no indications for investigation of the husband of Case 5 were considered to be present as this couple were childless (Fig. 3).

\section{Discussion}

None of our patients have had infections or other diseases which might cause these conduction disturbances. Therefore these must be considered as genetically determined.

Like Combrink et al. (1962) and Gazes et al. (1965), we find atrioventricular block as well as right-sided bundle-branch block in families with hereditary conduction disturbances.

In Cases I and 2 of the patients with hereditary atrioventricular block described by Tsagaris et al. (1967), alternation between atrioventricular block and sinus rhythm with right-sided bundle-branch block was found. Among the 19 published cases of hereditary right-sided bundle-branch block, including the present authors' cases, no transition from sinus rhythm to atrioventricular block was observed. It is therefore necessary to record several electrocardiograms to differentiate between the two groups of patients.

The 19 patients with hereditary right-sided bundle-branch block comprise ro male and 9 female patients. Six of the patients were children under the age of 14 years and 13 were adults aged $19-67$ years, the average age being 38 years. None of the patients had symptoms of cardiac disease and no deaths were described. The diagnosis was not established in any case at birth, and in Case 3 in the present series no bundle-branch block was present at the age of 7 years but was present at the age of 33 years. Hereditary right-sided bundlebranch block is, therefore, not necessarily congenital.

The 32 published cases, including Case I from this series, with electrocardiographically confirmed atrioventricular block comprise 2 I male and II female cases. Six of them died in infancy and 8 died between 3-65 years, the average duration of life being 31 years. Of the 8 patients, 7 survived from $I$ day to 3 years after the first Adams-Stokes seizure. Case $I$ in the present series thus differed from the remainder in that she survived for 35 years after the first Adams-Stokes seizure. A further patient died because of failure of an implanted pacemaker.

Seventeen of the patients were alive at the time of publication, including to children under the age of I4 years, and 7 adults aged 25-67 years with an average age of 45 years. Only I of the 17 patients had dyspnoea and oedema which disappeared after implantation of a pacemaker (Tsagaris et al., 1967). Three of the 17 patients had children after the diagnosis of atrioventricular block had been established. One patient reported by Khorsandian et al. (1964) completed three pregnancies without Adams-Stokes seizures, while, in one of the patients of Gazes et al. (1965), the first Adams-Stokes seizure occurred during the sixth pregnancy at the age of 35 years. Case I of the present series had Adams-Stokes seizures before she became pregnant and no change in the incidence of seizures occurred during her pregnancies. As far as can be judged from the cases presented, pregnancy thus does not appear to predispose to Adams-Stokes seizures or increased incidence of such attacks in patients with hereditary atrioventricular block.

Out of the 17 surviving patients with hereditary atrioventricular block, I had first degree block and 5 had second degree block. Six of the II patients with third degree atrioventricular block had Adams-Stokes seizure and, in 3 of them, pacemakers were implanted at the ages of $2 \frac{1}{2}, 46$, and 59 years.

Artificial pacemaking has considerably improved the prognosis for patients with atrioventricular block and, as such block may be hereditary, it is reasonable to investigate parents and sibs of young patients with bundle-branch block and atrioventricular block.

\section{References}

Combrink, J. M., Davis, W. H., and Snyman, H. W. (I962). Familial bundle-branch block. American Heart fournal, 64, 397.

FIG. 3 Pedigree of family.

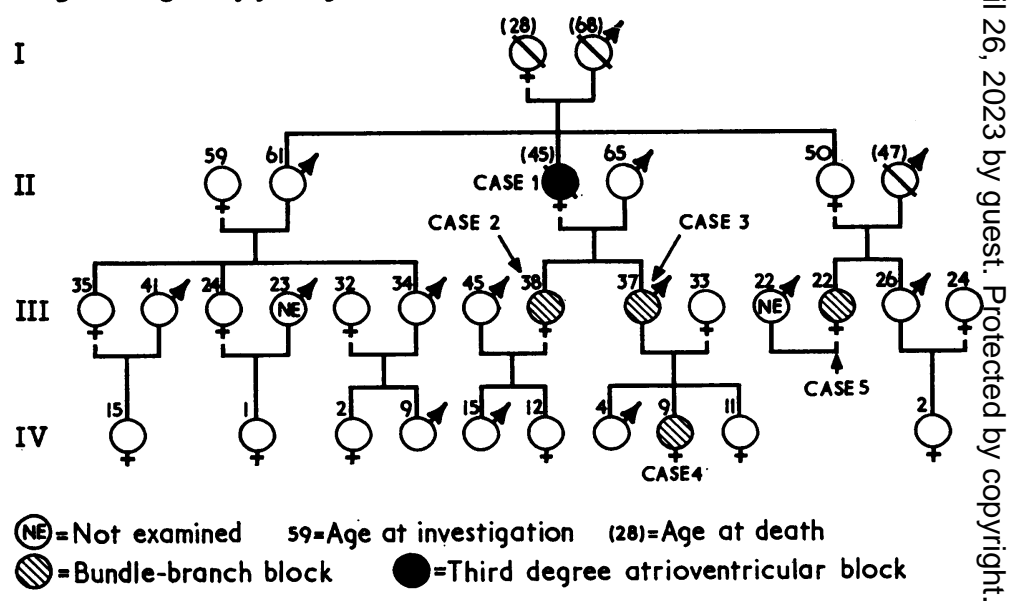


Connor, A. C., McFadden, J. F., Houston, B. J., and Finn, J. L. (1959). Familial congenital complete heart block. Case report and review of the literature. American fournal of Obstetrics and Gynecology, 78, 75 .

Crittenden, I. H., Latta, H., and Ticinovich, D. A (1964). Familial congenital heart block. American Fournal of Diseases of Children, 108, r04.

DeForest, R. E. (1956). Four cases of 'benign' left bundle branch block in the same family. American Heart fournal, 51, 398.

Gazes, P. C., Culler, R. M., Taber, E., and Kelly, T. E. (1965). Congenital familial cardiac conduction defects. Circulation, 32, 32.

Khorsandian, R. S., Moghadam, A.-N., and Müller, O. F. (1964). Familial congenital A-V dissociation. American fournal of Cardiology, I4, II8.

Lynch, R. J., and Engle, M. A. (I96I). Familial congenital complete heart block. American fournal of Diseases of Children, 102, 210.

Martínez Aparicio, A. (195I). Bloqueo incompleto de rama izquierda familiar. Revista Cubano de Cardiologia, 12, 15.
Mosetti, A. (1954). Blocco di branca familiare. Folia Cardiologica, 13, 527.

Stéphan, E. (I96I). Bloc auriculo-ventriculaire familial. Archives des Maladies du Coeur et des Vaisseaux, 54, 333.

Trivella, P., and Chella, S. (1960). Blocco di branca destra familiare e congenito. Minerva Cardioangiologica, 8, 186.

Tsagaris, T. J., Bustamante, R. A., and Friesendorff, R. A. (1967). Familial heart disease. Diseases of the Chest, 52, 153.

Veracochea, O., Zerpa, F., Morales, J., Hernandez, O., and Waich, S. (1967). Pacemaker implantation in familial congenital A-V block complicated by Adams-Stokes attacks. British Heart fournal, 29, 8 ro.

Wallgren, G., and Agorio, E. (1960). Congenital complete A-V block in three siblings. Acta Paediatrica (Uppsala), 49, 49.

Wendkos, M. H., and Study, R. S. (1947). Familial congenital complete A-V heart block. American Heart fournal, 34, 138. 